\title{
BMJ Open On-the-farm cardiovascular risk screening among migrant agricultural workers in Southeast Minnesota: a pilot prospective study
}

Tamim Rajjo, ${ }^{1}$ Khaled Mohammed, ${ }^{2}$ Jennifer Rho, ${ }^{3}$ M. Hassan Murad ${ }^{4}$

To cite: Rajjo T, Mohammed K, Rho J, et al. On-thefarm cardiovascular risk screening among migrant agricultural workers in Southeast Minnesota: a pilot prospective study. BMJ Open 2018;8:e019547. doi:10.1136/ bmjopen-2017-019547

- Prepublication history and additional material for this paper are available online. To view these files, please visit the journal online (http://dx.doi org/10.1136/bmjopen-2017019547).

Received 25 September 2017 Revised 1 May 2018 Accepted 22 June 2018
Check for updates

(C) Author(s) (or their employer(s)) 2018. Re-use permitted under CC BY-NC. No commercial re-use. See rights and permissions. Published by BMJ.

${ }^{1}$ Department of Family Medicine, Mayo Clinic, Rochester,

Minnesota, USA

${ }^{2}$ Department of Pediatrics, University of Minnesota,

Minneapolis, Minnesota, USA

${ }^{3}$ Community Health Services

Inc., Rochester, Minnesota, USA

${ }^{4}$ Division of Preventive,

Occupational and Aerospace

Medicine, Mayo Clinic,

Rochester, Minnesota, USA

Correspondence to

Dr Tamim Rajjo;

rajjo.tamim@mayo.edu

\section{ABSTRACT}

Introduction Accessibility to healthcare services is a major concern facing migrant agricultural workers (MAWs) in the USA. We aimed to test the feasibility of implementing cardiovascular risk screening at farm sites.

Methods This was a pilot prospective cohort study providing on-site monthly screenings of cardiovascular risk factors. We estimated the prevalence of cardiovascular risk factors and evaluated the success of this approach via modified validated satisfaction surveys.

Results We enrolled 38 MAWs and diagnosed 18 cases of pre-diabetes, diabetes, hypertension and hyperlipidaemia in 15 subjects (39.4\%). Mean scores of workers' satisfaction were high $(\geq 4)$ on a 5-point scale except 'Time spent with provider'. Over $80 \%$ of workers were likely to use this model if it was permanently available on the farm. Only $8.7 \%$ of workers were able to follow up after referral to a clinic.

Conclusions Cardiovascular risk factors are highly prevalent in MAWs. On-the-farm screening is a feasible and satisfactory model of healthcare delivery; however, other barriers continue to hinder MAWs from receiving follow-up care.

Trial registration number NCT02418637. Results.

\section{INTRODUCTION}

The production of agricultural products in the USA has been dependent on hand labour provided by migrant agricultural workers (MAWs). Since the early 1900s, MAWs have become a distinctive entity of the work force in the USA. The Department of Labour defines a migrant farmworker as "a seasonal farmworker who had to travel to do the farm work so that he/she was unable to return to his/her permanent residence within the same date". "Estimates of the numbers of MAWs in the USA vary enormously. The National Agricultural Workers Survey in 2010 estimated over 3 million migrant and seasonal farmworkers in the USA, ${ }^{23}$ with $75 \%$ of them born in Mexico and around $42 \%$ entered the USA within the 5 years prior to survey. ${ }^{4} \mathrm{MAWs}$ are predominantly men with only one in five
Strengths and limitations of this study

Prospective outreach study design with an underserved population.

- This study introduces a novel approach of healthcare delivery in the farming industry.

- Pilot study with a small sample size.

Potential selection bias.

workers is a woman and 1 in 20 is under the age of $18 .^{5}$

Cardiovascular risk factors, including obesity, type 2 diabetes and hypercholesterolaemia, are more prevalent in the MAWs and Hispanics than the general US population. While US Hispanics have similar or lower rates, MAWs were found to have higher prevalence of hypertension than non-Hispanic whites. Moreover, control of these chronic health conditions is poorer in the Hispanic population in general, causing greater disease complications. ${ }^{6-11}$ More importantly, MAWs perceive their health status as significantly poor ${ }^{9}$ and healthcare delivery to MAWs remains suboptimal, particularly for primary healthcare and preventive services. ${ }^{5} 1213$ Some of the barriers for accessing healthcare services are similar to those experienced by other immigrant Hispanic communities in the USA, including cultural and linguistic differences, low educational attainment, and financial and medical insurance challenges. Other barriers unique to MAWs are frequent mobility, residence on or close to farms with inadequate transportation, irregular employment and working long hours (25\% reported working 50 hours or more/ week). ${ }^{514}$

Legislation in the 1960s provided funding for a national system to facilitate healthcare delivery for MAWs in devoted clinics that usually offer income-based sliding scale fees and bilingual staff. Mobile clinics have 
been another solution to improve accessibility. ${ }^{15}$ Some programmes attempt more organised campaigns offering advanced screening (eg, mammography, bone density and respiratory diseases). Nevertheless, the lack of reliable transportation and inability of workers to leave job duties remain as significant barriers. ${ }^{16-19}$

Considering all these challenges, different healthcare delivery models are needed. Health screening at the worksite is one possibility to reduce some of these barriers and has been evaluated and proven to be associated with high degree of acceptability and adherence for up to 2 years. ${ }^{20}{ }^{21}$ However, such reports targeted urban workers, not MAWs. To our knowledge, there has been no research evaluating cardiovascular risk factor screening in MAWs at their worksite (on the farm). Therefore, we have conducted this pilot prospective study to evaluate the feasibility and acceptability of performing biometric and cardiovascular screening on the farm.

\section{METHODS}

\section{Study design and sample selection}

We designed a 6-month prospective cohort study with monthly visits to farm sites for testing blood pressure, glucose, lipid panel and weight. Surveys of feasibility and satisfaction were delivered at the end of the study period. We collaborated with the University of Minnesota Extension Program in Southeast Minnesota to reach out to farms listed in their database. We sent an email message to eight farms in the region outlining the research question, setting, population and timeline. Two dairy farms expressed interest in participation, one in Lewiston MN (total 11 workers) and the other in Canon Falls MN (total 15 workers). A third farm in St. Charles MN (20 workers) expressed interest after referral from one of the participating farms. After initial introductory visits to the farms, farms owners agreed to participate and introduced the project to their workers. Participation was voluntary and all participating workers signed a consent form.

\section{Patient and public involvement}

There was no patients' or public involvement in this pilot study.

\section{Inclusion and exclusion criteria}

We included male and female adult (18 years and older) migrant workers who were directly involved in agricultural work at farm sites. We excluded workers who were not directly involved in agricultural work (eg, accountants, administrative, etc).

\section{Data collection}

\section{Demographics}

On the initial visit, all participants filled out a basic demographic questionnaire that also included information about their cardiovascular medical history (hypertension, diabetes and hyperlipidaemia), smoking status, level of

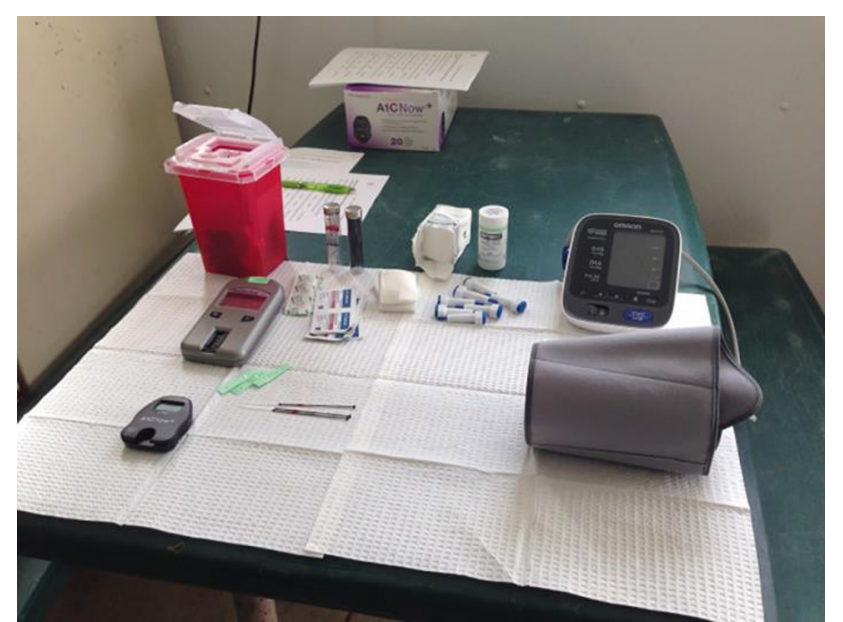

Figure 1 Screening station.

education and family size as well as years of working on their current farm and in farming in general.

\section{Cardiovascular risk factors}

A bilingual staff was available at all times. Using Clinical Laboratory Improvement Amendments-waived testing, the study principal investigator measured participants' blood pressure, glucose, cholesterol and HgA1C. Blood pressure was measured monthly using OMRON (OMRON Healthcare, Lake Forest, Illinois, USA). Blood glucose and cholesterol were also assessed monthly using CardioChek (PTS Diagnostics, Indianapolis, Indiana, USA) with PTS Panels test strips. Glycated haemoglobin was tested every 3 months using A1CNow (PTS Diagnostics). Weight was measured monthly using EatSmart scale (Health Tools LLC). Testing took place at a room designated by the farm owner (break room or meeting room) ensuring privacy and access to all participants. Testing took 15-20 min for each subject and was coordinated between farm owners and workers at each farm to avoid work interruption. A picture of the screening station is illustrated in figure 1.

Blood pressure was measured in the sitting position, in the right arm (when possible), after a 5 min rest. Abnormal blood pressure was considered with systolic pressure $\geq 140 \mathrm{~mm} \mathrm{Hg}$ or diastolic pressure $\geq 90 \mathrm{~mm} \mathrm{Hg}$ on two consecutive monthly visits. Random blood glucose and cholesterol were measured with fingertip samples. Abnormal glucose and total cholesterol were considered with values $\geq 200 \mathrm{mg} / \mathrm{dL}$ for both. Haemoglobin A1C was reported as normal if $\leq 5.7 \%$, pre-diabetes if $5.8 \%-6.4 \%$ and diagnostic of diabetes if $\geq 6.5 \%$. Body Mass Index (BMI) was calculated by dividing a participant's weight $(\mathrm{kg})$ by their squared height $(\mathrm{m})$. Subjects with BMI 18.5$24.9 \mathrm{~kg} / \mathrm{m}^{2}$ were considered normal weight, $25.0-29.9 \mathrm{~kg} /$ $\mathrm{m}^{2}$ overweight and $\geq 30.0$ obese.

\section{Follow-up}

Participants with known or new diagnoses of hypertension, diabetes or hyperlipidaemia were referred for follow-up. Those who indicated having a personal physician were advised to follow up with their physician to 
discuss any new findings. Others with no primary care physician were referred to the Migrant Health Clinic in Rochester MN, which usually provides services to MAWs (and local underserved Hispanic population in general), and appointments were facilitated by study staff. We provided educational materials regarding basic lifestyle modifications to patients with newly diagnosed and borderline conditions (eg, DASH diet for hypertensive patients, normal body weight measures and dietary/ exercise recommendations for overweight and obese patients).

\section{Feasibility and satisfaction}

After completing the study, each participant was asked to fill out the modified validated patient satisfaction questionnaire (PSQ-18) that evaluates seven different dimensions of satisfaction with medical care: general satisfaction, technical quality, interpersonal manner, communication, financial aspects, time spent with provider, and accessibility and convenience. PSQ-18 is a widely used validated method for measuring recipient's satisfaction with medical service. In 18 questions and less than 5 min to complete, these seven areas of satisfaction are assessed with 5-point Likert scale and each area is scored by the average of its multiple questions (with 4-5 reflecting high, 3 moderate and 1-2 low satisfaction) ${ }^{22}$ (online supplementary tables Ia and Ib).

Participants were also asked to complete a short survey we developed asking them about the testing site as well as any concerns of employment insecurity as a result of the screening and if they would adhere to and/or recommend this model to other workers (online supplementary table II). Farm owners were also asked to reflect on their experience, difficulties in accommodating screenings and thoughts about the model's impact on workers' health and business improvement. Feasibility was evaluated by assessing participants' satisfaction, adherence and the likelihood of workers and farm owners to adopt the new model of healthcare delivery.

\section{Statistical analysis}

Data were entered in Microsoft Excel and analysed using SPSS (released 2009; PASW Statistics for Windows V.18.0). Categorical variables were presented as frequency and percentage. Continuous variables were presented as means \pm SD or median (range). Data were stratified based on gender, level of education and family size. We used a non-parametric Mann-Whitney $U$ test to identify the difference between two groups with a two tailed $p$ value of $<0.05$ indicating statistical significance.

\section{RESULTS}

\section{Baseline characteristics of the participants}

A total of 38 workers consented to participate in the study of which $30(79 \%)$ completed the 6-month follow-up. The remaining eight (21\%) were all lost to follow-up due to turnover of migrant workers on the three farms. The majority were men (32) and median age was 30 years. Twenty-six workers $(69 \%)$ reported ending their education in middle or high school, while the rest were elementary school educated and only one worker graduated high school. Only three workers (10\%) identified themselves as English proficient. In terms of baseline health, 29 workers $(71 \%)$ were either overweight or obese and seventeen $(45 \%)$ were active smokers. Table $1 \mathrm{~A}$ summarises participants' baseline characteristics.

\section{Cardiovascular risk factors in MAWs}

Over a 6-month period, screening detected 14 cases $(36.8 \%)$ of pre-diabetes, 2 cases $(5.3 \%)$ of diabetes, 1 case of hypertension (2.6\%) and 6 cases of hyperlipidaemia $(15.8 \%)$. Prevalence and incidence of these risk factors are outlined in table 1B. Of note, the one case of hypertension was symptomatic (worker reported feeling fatigued and short of breath at times). He was referred to the Migrant Health Clinic in Rochester, MN, but unfortunately he failed to show up for the appointment and was lost to follow-up in the study. All newly diagnosed cases were counselled and provided with educational materials about their conditions. They were all referred to the Migrant Health Clinic; however, only two patients $(8.7 \%)$ were able to follow up in clinic and two others with their primary care physician. The rest either did not have the time or the clinic was too far for them to follow up.

\section{Satisfaction and feasibility of MAWs with screening service}

Different areas of participants' satisfaction are presented in table 2. Subjects reported high satisfaction with scores above 4 on six of the seven tested areas including general satisfaction, technical quality, interpersonal manner, communication, financial aspects and accessibility and convenience all presented as mean $\pm \mathrm{SD}$. Time spent with the screening provider averaged a score of $3.86 \pm 1.6$, consistent with moderate satisfaction.

The vast majority $(93.3 \%)$ of participants agreed that the screening site was convenient and $66.6 \%$ reported the screening did not interfere with their work schedule. As depicted in figures 2 and 3, $80 \%$ did not believe the intervention would put them at risk for employment discrimination. Over $80 \%$ were likely to use this model if further implemented in the future and would recommend it to a coworker.

Stratified analysis was done to explore the relationship between different areas of satisfaction and different baseline criteria. No statistically significant differences in areas of satisfaction or feasibility were noted when different comparisons were made including cardiovascular burden (with risk factor vs without risk factor), family size (no family vs family) or educational status (less than middle school vs middle school and higher). Online supplementary tables IIIa, IIIb and IIIc describe the stratified analysis. 


\begin{tabular}{ll}
\hline Table 1A & Baseline characteristics of participants \\
\hline Variables & $\begin{array}{l}\text { Frequency (\%), median } \\
\text { (range) }\end{array}$ \\
\hline Age & $30(18-59)$ \\
Gender & $32(84.2 \%)$ \\
\hline Male & $6(16.3 \%)$ \\
\hline Female & $12(31.6 \%)$ \\
Level of education & $4(10.5 \%)$ \\
\hline Elementary & $22(57.9 \%)$ \\
\hline Middle school & $3(1-9)$ \\
\hline High school & 10 miles (1-35) \\
\hline Family size & \\
\hline Distance to closest medical \\
facility
\end{tabular}

Aware of healthcare resources in community

\begin{tabular}{|c|c|}
\hline Yes & $26(68.4 \%)$ \\
\hline No & $12(31.6 \%)$ \\
\hline \multicolumn{2}{|l|}{ Smoking status } \\
\hline Current use & $18(47.6 \%)$ \\
\hline Former user & $7(18.2 \%)$ \\
\hline Never used & $13(34.2 \%)$ \\
\hline \multicolumn{2}{|l|}{ Duration on current farm } \\
\hline$<5$ years & $33(86.8 \%)$ \\
\hline$\geq 5$ years & $5(13.2 \%)$ \\
\hline \multicolumn{2}{|l|}{ Duration of work in farming } \\
\hline$<5$ years & $28(73.7 \%)$ \\
\hline$\geq 5$ years & $10(26.3 \%)$ \\
\hline $\mathrm{BMI}$ & $28.06(20.7-36.7)$ \\
\hline $18-24.9$ & $9(23.7 \%)$ \\
\hline $25-29.9$ & $18(47.4 \%)$ \\
\hline$\geq 30$ & $11(28.9 \%)$ \\
\hline Systolic blood pressure & $126(102-159)$ \\
\hline Diastolic blood pressure & $78.5(65-101)$ \\
\hline Total cholesterol & $166(112-223)$ \\
\hline Random glucose & $101(78-318)$ \\
\hline HA1C & $5.5(4.5-8.3)$ \\
\hline
\end{tabular}

BMI, Body Mass Index.

\section{Satisfaction and feasibility of farm owners with screening service}

With a short survey at the end of the study, owners of the three participating sites expressed great satisfaction
Table 1B Prevalence and newly diagnosed cases of cardiovascular risk factors

\begin{tabular}{lll}
\hline CV risk factors & Detected at 1st visit & $\begin{array}{l}\text { Diagnosed } \\
\text { during study }\end{array}$ \\
\hline Pre-diabetes & 12 & 2 \\
Type 2 diabetes mellitus & 2 & 0 \\
Hypertension & 1 (+2 self-reported) & 0 \\
Hyperlipidaemia & 5 & 1 \\
\hline
\end{tabular}

with the screening process. In fact, all three found it easy to accommodate time and space for workers to be screened. They agreed that the screening may improve their workers' health and improve their farm business. Finally, they strongly stated that they would recommend this model to other farm owners; however, only two were extremely likely to adopt a permanent similar screening model. Farm owners reported that they do not provide medical insurance. One farm owner provides workers with extra cash on their paychecks designated as medical expense money. However, she did not require workers to spend that money in any particular way. The other two farm owners did not offer any type of monetary assistance towards medical expenses.

\section{DISCUSSION AND CONCLUSIONS}

This pilot prospective study demonstrated that cardiovascular risk factors are highly prevalent in MAWs. Screening on a farm worksite appears to be a feasible and satisfactory model of service in this population.

Although this population sample was relatively healthy with only two self-reported cases of hypertension initially, the majority were at higher risks of cardiovascular disease for being either smokers or overweight. Nevertheless, multiple undiagnosed and new cases of pre-diabetes, diabetes, hypertension and hyperlipidaemia were uncovered over the study period. Fifteen participants were identified with one or more $\mathrm{CV}$ risk factors but, as noted above, very few (2) were seen for follow-up at the Migrant Health Clinic and two others reported following up with a primary care provider. Other subjects (7) reported lack of time and long distance (4) of approximately 20 miles from our

\section{Table 2 Domains of satisfaction}

\begin{tabular}{ll}
\hline Area of satisfaction & Mean \pm SD \\
\hline General satisfaction & $4.46 \pm 0.79$ \\
\hline Technical quality & $4.48 \pm 0.65$ \\
Interpersonal manner & $4.43 \pm 0.89$ \\
\hline Communication & $4.45 \pm 0.75$ \\
\hline Financial aspects & $4.7 \pm 0.55$ \\
\hline Time spent with provider & $3.86 \pm 1.6$ \\
\hline Accessibility and convenience & $4.36 \pm 0.87$ \\
\hline
\end{tabular}




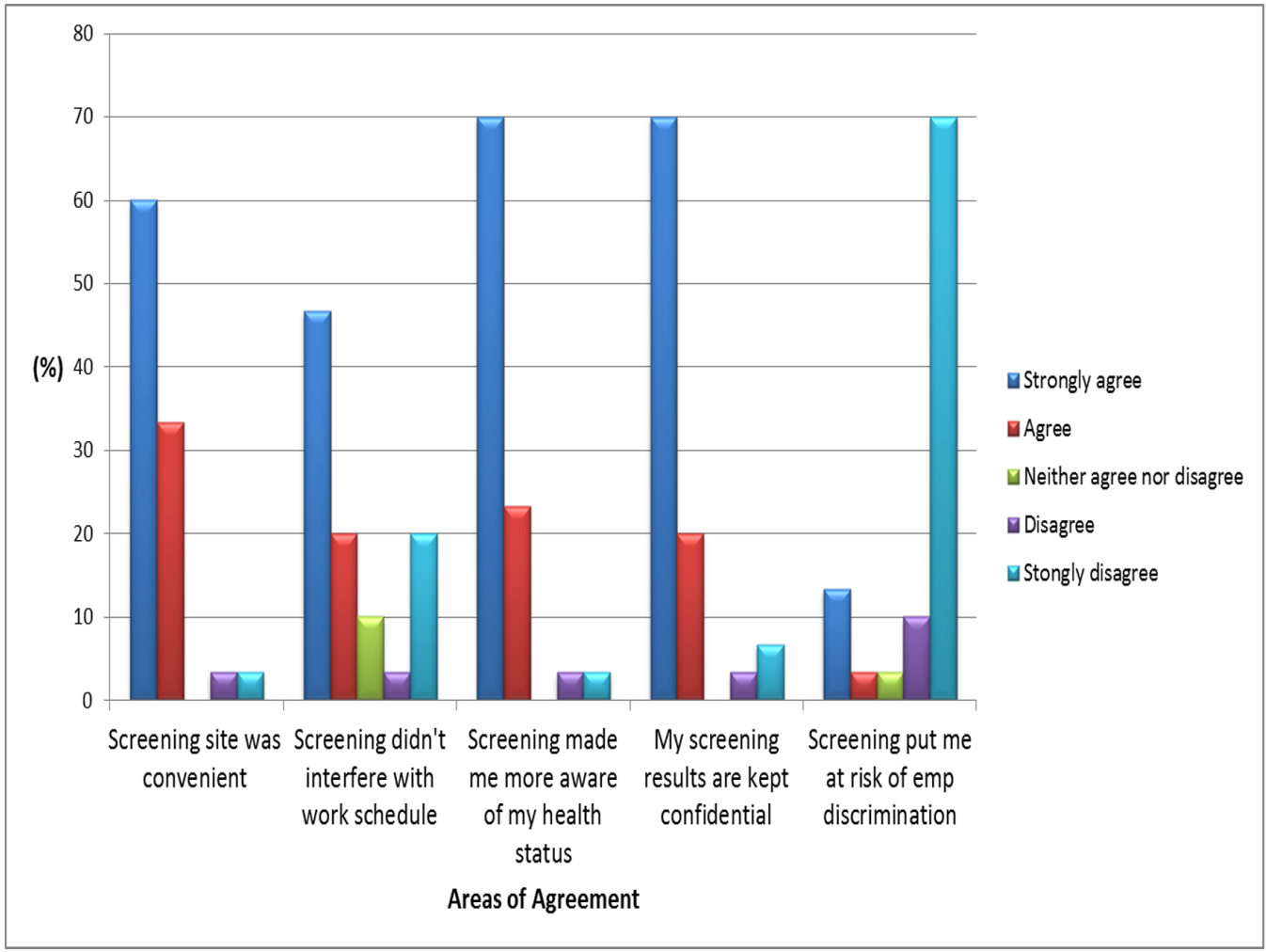

Figure 2 Final survey; different areas of agreement.

Migrant Health Clinic as main reasons for not scheduling a follow-up visit. Two participants with CV risk factors left their jobs before the study ended. Other possible reasons include access to insurance, residence status, and language and cultural barriers, which indeed match findings from previous research (5); however, the Migrant Health Clinic in Rochester MN has fulltime bilingual/Hispanic staff, does not require proof

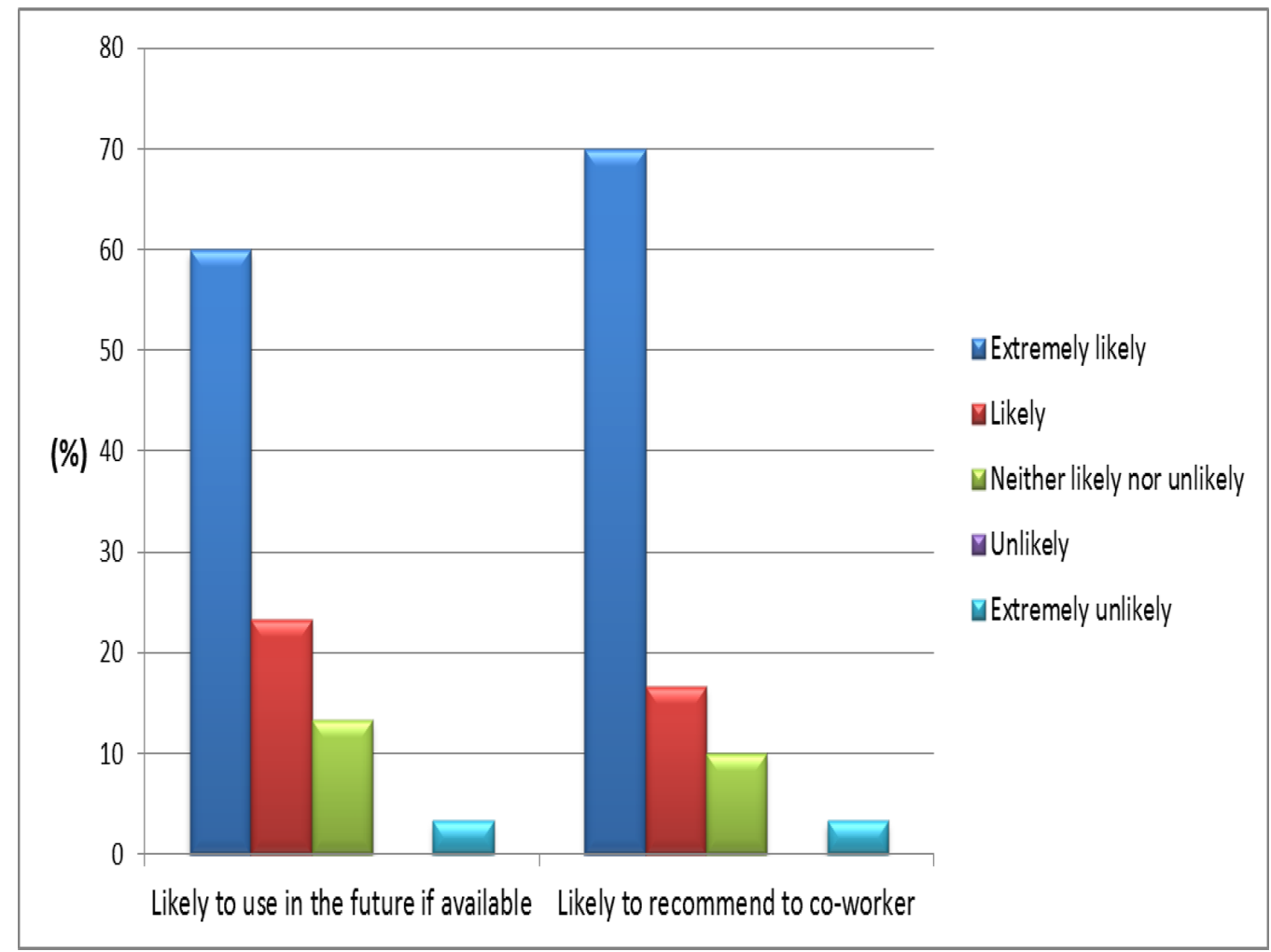

Figure 3 Final survey; likelihood of using or recommending this model. 
of residence and charges sliding scale fees based on income. Thus, we believe distance and nature of their work (as noted above, some work $>50$ hours/week) continue to represent the major barriers for follow-up on screening-detected diagnosis.

The literature overwhelmingly shows overall poor health, prevalent risk factors and great barriers to healthcare in farm workers. Discussions with farm owners confirmed that they do not offer workers medical insurance. Hence, new and innovative methods are needed to deliver care to this population. Screening on a farm worksite may be one of the approaches that can reduce barriers such as distance and work schedules and improve access. The intervention offered preventive measures that were free of charge and was facilitated by employers' buy-in. Accommodation of time and space, and the availability of a bilingual healthcare provider also ensured maximum participation of mostly non-English-speaking individuals. The challenge remains with the need for better solutions for follow-up. This proposed model of care focuses only on screening, diagnosis and education on the farm site. This pilot work provides a rationale for evaluating the delivery of additional services to MAWs at their work site, such as treatment and continuity of care. Such approach has been proven effective in other settings. Alderman for example 202324 tested the detection and treatment of hypertension at the worksite and reported improved adherence and better control of blood pressure, as well as less disability and hospitalisation days. However, Alderman's work took place in an urban setting and validation in farm setting may demonstrate the need to modify his approach to fit the unique needs, values and preferences of this unique population.

\section{Limitations}

The major limitations to this pilot study is the small sample size of MAWs and the attrition rate $(21 \%)$, although this attrition rate was expected due to the mobility and job instability among MAWs. Another possible limitation is the lack of crops and seasonal farms recruitment (sample included three dairy farms). Selection bias could have affected the results since participating farm owners (previously engaged in research projects with University of MN) may not represent other farm owners who may be less acceptant of health screening of their workers. We did not inquire whether MAWs were legal immigrants or H2-A visa holders. If any were illegal, they may have not had the ability to seek further follow-up.

Contributors All authors have substantially contributed to this pilot study. Study design: TR, JR, MHM. Data collection: TR, JR. Data analysis and interpretation: TR, KM. Manuscript writing: TR, KM, MHM. All listed authors have reviewed, revised and approved the final manuscript and agreed on accountability for all aspects of the submitted manuscript.

Funding This project was funded by University of Minnesota Upper Midwest Agricultural Safety and Health Center through sub-award (no. P004365208).

Competing interests None declared.

Patient consent Obtained.
Ethics approval The project was approved by the Institutional Research Board at Mayo Clinic in Rochester MN (Protocol 15- 000647) and is registered in ClinicalTrials.gov (ID NCT02418637).

Provenance and peer review Not commissioned; externally peer reviewed.

Data sharing statement All available data can be obtained by contacting the corresponding author.

Open access This is an open access article distributed in accordance with the Creative Commons Attribution Non Commercial (CC BY-NC 4.0) license, which permits others to distribute, remix, adapt, build upon this work non-commercially, and license their derivative works on different terms, provided the original work is properly cited, appropriate credit is given, any changes made indicated, and the use is non-commercial. See: http://creativecommons.org/licenses/by-nc/4.0/.

\section{REFERENCES}

1. Department of Labor. Who are Migrant and Seasonal Farmworkers: United States Depatment of Labor, 2013.

2. USDA. Number and Geographical Distribution of Hired FarmworkersUnited States Department of Agriculture2015.

3. Health, N.C.f.F.. Facts about Farmworkers: Farmworker Health Factsheet, 2012

4. Department of Labor. Place of Birth and Foreign-born Workers' First Arrival to the United States: The National Agricultural Workers Survey, 2010

5. Arcury TA, Quandt SA. Delivery of health services to migrant and seasonal farmworkers. Annu Rev Public Health 2007;28:345-63.

6. Egan BM, Zhao Y, Axon RN. US trends in prevalence, awareness, treatment, and control of hypertension, 1988-2008. JAMA 2010;303:2043-50.

7. Keenan NL, Rosendorf KA. Centers for Disease Control and Prevention (CDC). Prevalence of hypertension and controlled hypertension-United States, 2005-2008. MMWR Suppl 2011;60:94-7.

8. Pabon-Nau LP, Cohen A, Meigs JB, et al. Hypertension and diabetes prevalence among U.S. Hispanics by country of origin: the National Health Interview Survey 2000-2005. J Gen Intern Med 2010;25:847-52.

9. Slesinger DP. Health status and needs of migrant farm workers in the United States: a literature review. J Rural Health 1992;8:227-34.

10. Villarejo D. Suffering in silence: a report on the health of California's agricultural workers: NIOSH, 2000.

11. Villarejo D. The health of U.S. hired farm workers. Annu Rev Public Health 2003;24:175-93.

12. Rosenbaum S. Migrant and seasonal farmworkers: health insurance coverage and access to care: Kaiser Commission on Medicaid and the Uninsured, 2005.

13. Scott $\mathrm{G}, \mathrm{Ni} \mathrm{H}$. Access to health care among Hispanic/Latino children: United States, 1998-2001. Adv Data 2004;344:1-20.

14. National Center for Farmworker Health. Demographics: Farmworker Health Factsheet, 2012.

15. National Center for Farmworker Health. Migrant health program History and Legislation, 2014.

16. Carroll D. Findings from the National Agricultural Workers Survey (NAWS) 2001-2002: A Demographic and Employment Profile of United States Farm Workers. Rep, 9: U.S. Department of Labor, Office of the Assistant Secretary for Policy, 2005.

17. Lantz PM, Dupuis L, Reding D, et al. Peer discussions of cancer among Hispanic migrant farm workers. Public Health Rep 1994;109:512-20.

18. Schmalzried HD, Fallon LF. Reducing barriers associated with delivering health care services to migratory agricultural workers. Rural Remote Health 2012;12:2088.

19. Luque JS, Castañeda H. Delivery of mobile clinic services to migrant and seasonal farmworkers: a review of practice models for community-academic partnerships. J Community Health 2013;38:397-407.

20. Alderman $\mathrm{MH}$, Schoenbaum EE. Detection and treatment of hypertension at the work site. N Engl J Med 1975;293:65-8.

21. Sonkodi B, Fodor JG, Abrahám G, et al. Hypertension screening in a salami factory: a worksite hypertension study. J Hum Hypertens 2004;18:567-9.

22. Marshal $\mathrm{G}$. The patient satisfaction questionnaire short form (PSQ18): RAND Corporation, 1994.

23. Alderman $\mathrm{MH}$, Davis TK. Hypertension control at the work site. $J$ Occup Med 1976;18:793-6.

24. Alderman MH, Davis TK. Blood pressure control programs on and off the worksite. J Occup Med 1980;22:167-70. 